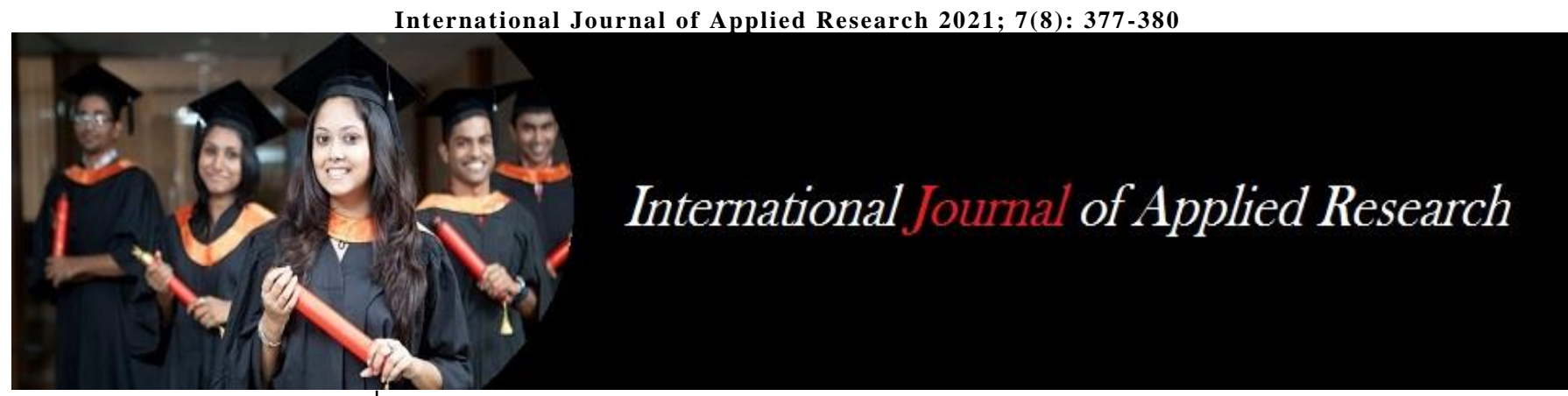

ISSN Print: 2394-7500 ISSN Online: 2394-5869 Impact Factor: 8.4 IJAR 2021; 7(8): 377-380 www.allresearchjournal.com Received: 01-06-2021 Accepted: 03-07-2021

Sameer Ahmad Dar M.Sc. Nursing, Medical Surgical Nursing (Gastroenterology Nursing), Tutor, Government College of Nursing, Baghi Dilawar Khan, Srinagar, Jammu and Kashmir, India

Humaira Qadir Lone M.Sc. Nursing, Mental Health Nursing, Tutor, Syed Mantaqui Memorial College of Nursing and Medical Technology, Awantipora, Pulwama, Jammu and Kashmir, India
Corresponding Author: Sameer Ahmad Dar M.Sc. Nursing, Medical Surgical Nursing (Gastroenterology Nursing), Tutor, Government College of Nursing, Baghi Dilawar Khan, Srinagar, Jammu and Kashmir, India

\section{A study to assess the effectiveness of structured teaching programme on knowledge and attitude regarding prevention of oral cancer among tobacco users in selected area, Bangalore}

\section{Sameer Ahmad Dar and Humaira Qadir Lone}

DOI: https://doi.org/10.22271/allresearch.2021.v7.i8f.8888

\section{Abstract}

Title: A study to assess the effectiveness of structured teaching programme on knowledge and attitude regarding prevention of oral cancer among tobacco users in selected area, Bangalore.

Objectives: To determine the effectiveness of structured teaching programme on knowledge and attitude regarding prevention of oral cancer among tobacco users.

Materials and Methods: An evaluative one group pre-test and post-test pre-experimental design was used. With the purposive sampling 60 study participants were selected. Tool used in this study included three sections, Section-I including demographic Performa of tobacco users such as age, education, occupation, previous knowledge regarding oral cancer, years of smoking/tobacco use and personal habit of using tobacco, Section-II Including close ended structured knowledge questionnaire with 30 items regarding knowledge and management of oral cancer, while Section-III used attitude rating scale with 15 items. STP was administered after conducting pre-test and post-test was conducted after 7 days. Data was analyzed by using descriptive and inferential statistical technique.

Result: The data analysis revealed that the post-test knowledge score $69.44 \%$ was higher than that of pre-test knowledge score $40.78 \%$.

Conclusion: The study concluded that the structured teaching programme (STP) on prevention of oral cancer was an effective method of enhancing the knowledge and changing the attitude of tobacco users regarding prevention of oral cancer.

Keywords: effectiveness, STP, knowledge, attitude, prevention, oral cancer

\section{Introduction}

Oral cavity or mouth is a complex system that you rely for a number of everyday functions, from talking to enjoying a meal. Experts say that your mouth is a window into your body's health. A healthy mouth is a healthy life. Mouth or oral cancer refers to cancer that develops in any of the part that make up the mouth. Oral cancer incidence in India accounts for 86\% globally. India continues to report the highest prevalence of oral cancers globally with 75,000 to 80,000 new cases of such cancers reported every year. In India, tobacco alone is responsible for 1.5 lakh oral cancers, 4.2 million heart diseases and 3.7 million lung diseases every year. India is oral cancer capital of world because of rampant habit of tobacco chewing.

\section{Need of the Study}

Annually, over 30,000 new cases of oral cancer are diagnosed all over the world where majority are diagnosed in advanced stages. Such data make oral cancer an important public health matter which is responsible for $3 \%$ to $10 \%$ of cancer mortality worldwide. It is estimated that oral cancer deaths are due to tobacco use, unhealthy diets, alcohol consumption and inactive lifestyles. A survey was conducted by ministry of health and family welfare, government of India regarding the tobacco use in Karnataka. A study sample of 30,000 persons aged over 10 years was selected by random sampling technique. The result showed that $29.6 \%$ were using tobacco and this study revealed that people from lower 
socioeconomic status are usually more likely to use tobacco. According to the hospital based cancer registry of Bangalore, oral cancer is high among women with $12.5 \%$ of women acquiring the disease. The registry reveals that $11.2 \%$ of all cancers among men and $13.7 \%$ of cancers in women in the city are oral cancers. Kolar has a high percentage of oral cancers in state. Studies have reported an alarming lack of knowledge and attitude about prevention of oral cancer among tobacco user's despite of numerous advertisements and health hazard warnings printed on tobacco and tobacco products, gutkha packets and this need is to be addressed by further public education possibly the tobacco user groups. It is important to understand the existing knowledge of specific population at risk. Which will provide important clause to develop strategies for controlling the incidence of oral cancer among population

\section{Objectives of the study}

1. To assess the knowledge regarding prevention of oral cancer among tobacco users.

2. To assess the attitude regarding prevention of oral cancer among tobacco users.

3. To determine the effectiveness of structured teaching programme on knowledge and attitude regarding prevention of oral cancer among tobacco users.

4. To find the association between post-test knowledge regarding prevention of oral cancer among tobacco users with their selected demographic variables.

5. To find the association between post-test attitude regarding prevention of oral cancer among tobacco users with their selected demographic variables.

\section{Methodology \\ Research Approach: Evaluative approach}

Research Design: Pre-experimental, i.e., one group pre-test and post-test design was adopted.

Research Setting: Study Samples were selected from Attur Layout, Bangalore.

Population: The population under study are tobacco users who attended the health talk on oral cancer in selected area Attur Layout, Bangalore.

Sample: Tobacco users in selected area Attur Layout,
Bangalore.

\section{Sample Size: 60 .}

Sampling Technique: Non-probability purposive sampling technique.

\section{Criteria for Sample Selection \\ Inclusion criteria}

Tobacco users present available at the time of data collection.

Data Collection tool: A closed ended structured questionnaire and attitude rating scale was prepared to measure the dependent variable before and after the administration of structured teaching programme.

\section{Results}

\section{Findings related to demographic characteristics of the subject}

Age wise distribution of study samples revealed that majority of the samples $58.33 \%$ were in the age group of 2030 Years. Among all the participant's majority of the respondents $45 \%$ had secondary education. Sample distribution with regard to their occupational status revealed that most of respondents $36.66 \%$ were private employees. Percentage distribution of samples according to previous knowledge regarding oral cancer revealed that highest percentage of respondents $63.33 \%$ didn't had any previous knowledge regarding oral cancer. Findings of the study also revealed that majority of respondents $56.6 \%$ were using tobacco/smoking from past 1-5 years. The findings related to personal habit of tobacco use, in which form revealed that majority of respondents $61.6 \%$ have habit of using tobacco in both smokeless and smoking form.

\section{Findings related to pre-test knowledge and post-test knowledge scores of study subjects}

The findings revealed that the majority of the study subjects $61.7 \%$ had moderate pre-test knowledge and post-test knowledge scores of the study subjects showed that majority of the study subjects $55 \%$ had adequate post-test knowledge.

3. Findings related to pre-test attitude and post-test attitude scores of study subjects

Table 1: Shows pre-test sand post-test attitude scores regarding prevention oral cancer $\mathrm{N}=60$

\begin{tabular}{|c|c|c|c|c|c|c|}
\hline \multicolumn{2}{|c|}{ Attitude level } & \multirow{2}{*}{ Category } & \multicolumn{2}{c|}{ Pre-test } & \multicolumn{2}{c|}{ Post-test } \\
\cline { 4 - 7 } & & & Frequency & Percentage & Frequency & Percentage \\
\hline a. & Unfavorable attitude & $\leq 25$ Score & 13 & 21.7 & 0 & 0 \\
\hline b. & Moderately favorable attitude & $\geq 26-50$ & 47 & 78.3 & 47 & 78.3 \\
\hline c. & Favourable attitude & $\geq 51-75$ & 0 & 0 & 13 & 21.7 \\
\hline Total & & & 60 & 100 & 60 & 100 \\
\hline
\end{tabular}

4. Findings related to effectiveness of structured teaching programme on knowledge and attitude regarding prevention of oral cancer among tobacco users

Table 2: Shows calculated paired ' $t$ ' test value of 25.382 which was greater than the table value at 0.05 level of significance

\begin{tabular}{|c|c|c|c|c|c|c|c|c|}
\hline Knowledge & Mean & S.D. & Mean \% & Mean difference & Paired T test & P Value & Table value at 0.05 & N=60 \\
\cline { 1 - 6 } & 12.23 & 3.461 & 40.78 & 8.600 & 25.382 & $<0.001$ & 2.00 & Result \\
\hline Pre & 20.83 & 1.976 & 69.44 & & & & Significant \\
\hline
\end{tabular}

Significant at 0.05 level 
Table-2 shows calculated paired ' $t$ ' test value of 25.382 which was greater than the table value at 0.05 level of significance, which indicates that there is a significant difference between mean pre-test and post-test knowledge scores of respondents and showed that STP was effective in increasing the knowledge of study subjects regarding prevention of oral cancer.

The pre-test mean attitude was 28.45 and mean attitude percentage was 37.93 with SD \pm 3.916 and the mean posttest attitude was 45.37 and mean attitude percentage was 60.49 with $\mathrm{SD} \pm 5.892$ with mean difference of 16.917 . The calculated paired ' $t$ ' test value of 23.247 was greater than the table value at 0.05 level of significance, which indicates that there is a significant difference between mean pre-test and post-test knowledge scores of respondents and showed that STP was effective in changing the attitude of study subjects regarding prevention of oral cancer.

5. Findings related to association of post-test knowledge and attitude scores of study subjects with their selected demographic variables

Table 3: Shows there was a significant association between the post-test knowledge score of study subjects regarding prevention of oral cancer and the previous knowledge regarding oral cancer, which is ruled out by Chi-square-test

\begin{tabular}{|c|c|c|c|c|c|c|c|c|c|}
\hline \multirow{2}{*}{\multicolumn{3}{|c|}{$\begin{array}{c}\text { Association with Demographic } \\
\text { Variables }\end{array}$}} & \multirow{2}{*}{\multicolumn{2}{|c|}{ Post Knowledge }} & \multirow[b]{3}{*}{ Chi Test } & \multirow[b]{3}{*}{ P Value } & \multirow{3}{*}{\multicolumn{2}{|c|}{\begin{tabular}{|l|l|} 
df & Table Value \\
\end{tabular}}} & \multirow[b]{3}{*}{ Result } \\
\hline & & & & & & & & & \\
\hline Variable & Options & Adequate & Moderately Inadequate & Inadequate & & & & & \\
\hline Previous & \multirow[b]{2}{*}{ Yes } & \multirow{2}{*}{17} & \multirow{2}{*}{5} & & \multirow{4}{*}{6.962} & \multirow{4}{*}{0.008} & \multirow{4}{*}{1} & \multirow{4}{*}{3.841} & \multirow{4}{*}{ Significant } \\
\hline Knowledge & & & & & & & & & \\
\hline Regarding Oral & \multirow[t]{2}{*}{ No } & \multirow{2}{*}{16} & \multirow{2}{*}{22} & & & & & & \\
\hline Cancer & & & & & & & & & \\
\hline
\end{tabular}

Table-3 shows there was a significant association between the post-test knowledge score of study subjects regarding prevention of oral cancer and the previous knowledge regarding oral cancer, which is ruled out by Chi-square-test. There was no significant association between the post-test knowledge scores of study subjects regarding prevention of oral cancer and other demographic variables like age, education, occupation, years of smoking/tobacco use and personal habit of using tobacco. Analysis revealed that there was no significant association between the post-test attitude score with the selected demographic variables.

\section{Acknowledgement}

We will like to extend our sincere gratitude to all the participants for taking part in our study and making this study a success. We will also like to thank all the concerned authorities for granting us permission to conduct this research.

\section{Discussion}

A programmed health education regarding identification of signs and symptoms of oral cancer and its management and prevention could be arranged by health professionals in nursing homes and community. Health professionals must take actions in order to identify the clients with oral cancers and motivate them to practice facial exercises/therapies to improve functional performance. The nursing personnel should be encouraged to conduct educational programs in community areas to help in imparting knowledge regarding oral cancer and making them aware regarding its prevention. In-service education can be planned for the nurses to keep them updated with various alternative therapies and nonpharmacological treatments related to oral cancer. Pamphlets on oral cancer and its prevention can be distributed so that it can bring about an awareness among general masses especially tobacco users.

\section{Conclusion}

Most of the samples $58.33 \%$ were in the age group of 20-30. Most of the participants $45 \%$ had completed their S.S.L.C. Findings related to occupation of the participants' showed that majority of tobacco users $36.66 \%$ were private employees.

Samples showed that $63.33 \%$ didn't had any previous knowledge regarding oral cancer.

Distribution of study subjects according to years they have smoked or used tobacco revealed that majority of respondents $56.6 \%$ were using tobacco/smoking from past 1-5 years. The findings of the present study revealed that majority of respondents $61.6 \%$ have habit of using tobacco in both smokeless and as well as smoking form. The findings revealed that the majority of the study subjects $61.7 \%$ had moderate knowledge regarding oral cancer, $36.7 \%$ of the respondents had inadequate knowledge while as only $1.7 \%$ of the respondents had adequate pre-test knowledge. Results also revealed that the majority of study subjects $78.3 \%$ had moderately favorable attitude towards oral cancer, $21.7 \%$ had unfavorable attitude and no study subject was having favorable attitude. After implementing STP, the post-test findings showed significant increase in the knowledge of tobacco users and changing the attitude regarding prevention of oral cancer. Therefore, structured teaching programme is proved to be one of the effective teachings methods.

\section{References}

1. Introduction to oral health. Available at: www.mayoclinic.com and www.sharecare.com.

2. What is Cancer? Available at: www.medicinenet.com

3. Introduction to cancer and how common is cancer. Available at: www.nidirect.gov.uk

4. Cancer Incidence. Available at: www.deccanherald.com

5. Incidence and Prevalence of Oral Cancer. Available at: http://ocf.org.in/professional/incidenceand prevalence.aspx.

6. Reddy M, Gupta PC. Report On Tobacco Control in India, New Delhi: Ministry of Health and Family Welfare, Govt. of India 2004.

7. Dr. Vijay. Oral cancer on rise among city women. The Hindu Online ed. Of India's National Newspaper, Monday 2005.

8. Oral Cancer Facts. The Oral Cancer Foundation. Available at: www.oralcancerfoundation.org/facts/ 
9. Oral cavity cancer. Available at: http://www.sharecare.com/health/lip-oralcancer/howseriousisoralcancer

10. Ken Russell Coelho. Challenges of the oral cancer Burden in India. Journal of Cancer Epidemiology 2012, Article id: 701932, 17 pages. Available at: http://dx:doi.org/10.1155/201 